\title{
Review on Facebook Impact on Social Life of Ethiopia University Student
}

\author{
Lisanu Damene Daracho \\ Jimma University P.O.Box 307 Jimma Ethiopia
}

\begin{abstract}
Facebook use in university students of Ethiopia has been highly increased in last years and is hihly used social media among other social networking sites. This review examines the Facebook impact on social life on university student of Ethiopia. University is one of higher education institutions have great fear that student academic performance might affect adversely because students are paying more attention towards Facebook. Time wastage, developing psychological disorders, addiction to user, social aspect of life, predict or influence student behavior, decreases students grade are the negative impacts of Facebook on university students. Students use their smart phone and laptop to Facebook and they use Facebook to interacting, publishing, sharing things, mailing, chatting, posting purposes and academic accumulation of resources.
\end{abstract}

DOI: $10.7176 / \mathrm{IKM} / 10-5-03$

Publication date: August $31^{\text {st }} 2020$

\section{Introduction}

Now a day communication has developed since ages as civilization and development goes hand in hand. In $21 \mathrm{st}$ century the communication is faster, better and efficient the credit goes largely to technology. Internet has highly changed the human experience. Socialization is an important aspect of this technology. All internet users indicate one of their primary purposes for going online is for communication purpose (Mesfin et al., 2017).

The use of social media in 21 st century is increasingly and becoming popular among the youths and higher education students in worldwide due to their interactive features (Lev-on, 2017). Social media constitute websites that are designed to enable users to share information, exchange ideas and pears, and participate in content modification online. These involve the platforms Facebook, YouTube, Twitter, Instagram, Skype, Yahoo, Telegram, LinkedIn, Google+ and other similar interactive websites. These are widely in use among public services and students in different levels of education (Dhir and Tsai 2017).

Online social networks has now spread round most part of the globe and Facebook is world's first social network become so popular for young people that they hardly use email or other way of communication (Kirkpatrick, 2010). People use Facebook to stay connected with friends, relatives and family, to be informed and entertained within their social circle, and to share and express what matters to them (Facebook facts, 2013).

The effects of increasing information technology on campus have mostly link with academic learning's and academic performances. But due to popularity of Facebook in university campuses the link with academic learning's by the information technology may be affected. Some recent research works are indicating the impact of Facebook on students' academic performances. It is necessary to define the academic performance before we go any further. The academic performance is a function of attention span, time management skills, student characteristics, academic competence, time spent on Facebook and academic competence is defined as a student's ability to manage the required course load and course materials for his/her chosen field of study (Aliyas, Hope and Justin, 2012).

Most social media services provide activities like chatting, commenting, voting, updating status and sharing of information for their users. Facebook and other social media made it easy to share photos person and others, videos, ideas, likes and dislikes, with the world and also made it fast to know and receive what people commented on them. Social networking sites often include social media platforms to facilitate interactions and conversations among people in a virtual community (Kaplan \& Haenlein, 2010).

Facebook user holding the largest percentage of member in online social network today and most of them are students around the world. Use of the Facebook might have good or bad impacts on their academic performance and academic lives. The excessive use of Facebook among the students is generating main question that is Facebook use effecting on students' academic performance and playing positive or negative role in their social and academic lives (Kirkpatrick 2010).

The personal risks that frequently happen to young students on social media involve uploading unintended information in certain contexts; uploading negative information about oneself and the others; hacking others' accounts and being hacked; and using information for retaliation purposes, privacy problem, safety, and psychological well-being of youths (Błachnio et al., 2016). Academically, the excessive use of Facebook has counter effect on the students' academic pursuits by diverting their attention from education-oriented activities to recreational oriented activities (Tsitsika et al., 2014). Emotionally, the extensive use of social media can reduce peer interactions and may lead users to feel loneliness overtime and lead teenagers develop distorted image of 
self.

Facebook users are not necessarily "networking" or looking to meet new people; instead, they are primarily communicating with people who are already part of their extended social network (Porter, 2007). Facebook is an example of social networking websites. Developed by Mark Zuckerberg of Harvard University in February 2004, the site was originally developed for college and university students as a way to connect with each other (Philips, 2007). Students likely spend more time on social media per day than on academic activities. In particular, the duration of time students spend on Facebook alone seems to be equal with the time spent on academic activities. In Ethiopia believed that a large number of young students are active users (Feyisa and Dawit, 2018).

Education is very essential part of an individual's life for every young person. Today young students' shows very much interest for using social networks but unfortunately social networks affect education negatively. In Ethiopia most university students do not take their food on time and do not sleep on time which causes a very non serious attitude with education. They are not even bothered to solve their home tasks and they contact elders and seniors to help them in cloning their educational material. Social networks provide a virtual life to the students, those students who not even speak in front of anyone could feel freedom in their virtual life. When they use social networks they feel like in heaven but this addiction kills their inner self confidence for ever. Becoming addict of social networks feels like you have so many friends but in real all of the contacts are virtual contacts (Yirga, 2015).

This review paper have one general objective to Review on Facebook Impact on University Student Social Life in Ethiopia with specific objectives i) To review Facebook negative impacts on users' academic or career performance in Ethiopia. ii) To identify the relationship between times spend on facebook and academic performance of university students in Ethiopia and iii To identify the main reasons as to why university students of Ethiopia use Facebook.

\section{Overview of Social Media}

\subsection{Use of social media}

Social media has a history dating back to the 1970s. Social media is that means that employs mobile and web based technology to create highly interactive platforms via which individuals and community share, co-create, discuss and modifies user-generated content (Kietzmannn, 2012). The idea that social media are defined by their ability to bring people together has been seen as too wide a definition, as this would suggest that the telegraph and telephone were also social media - not the technologies scholars are intending to describe.

Common social media in using are Friendster, Facebook, Myspace, youtube, photobucket, flicker, and other sites aimed at photo and video sharing. Martn, (2008) and Lusk, (2010) share the same concept of social media. Facebook, Blogs, Twitter, My Space and LinkedIn used for the purpose of communication, sharing photos as well as videos. Facebook is considered as the largest social network site on the internet today. In February 2004 an undergraduate student of Harvard University Mark Elliot Zuckerberg launched The Facebook network site for the student of the university (Grossman, 2010). According to Heiberger \& Harper, 2008 Facebook is a synthesis of many Internet based communication tools previously in wide but disconnected use. Today, Facebook is embraced of almost all types of internet users, but students from the universities and colleges are the largest percentage of active Facebook users.

\subsection{Facebook use in Ethiopia}

According to Jibat (2012) In Ethiopia, among social networking sites, Facebook has been the prime among highly visited social networking sites. Currently, university has great fear that students academic performance might affect adversely because students are paying more attention towards social networking sites. In developed countries this area grasps researchers' attention but in developing countries like Ethiopia, it is unexplored area (Nebiat and Girum, 2014).

In Ethiopia it is expected the number of social media users will be increased dramatically, because of the following reasons: first, the government has started a $\$ 1.6$ billion project to expand $4 \mathrm{~g}$ network across the capital city of the country and $3 \mathrm{~g}$ network all over the country (Ethio Telecom, 2013); second, the population of Ethiopia is estimated around 99 million and most of them are young; finally, the number of Facebook users are increased at an alarming rate, for instance there is 35\% from 2013 to 2015 (Internet Usage and Population Statistics for Africa, 2015). Currently in Ethiopia above 22 million peoples use internet and from this number high number use Facebook. From this number of users' university students and adolescent play lion share (Ethio Telecom, 2020).

The study result of the Nebiat and Girum (2014) in Jimma University indicated that most of students use their personal Laptops and Mobile phone to visit Facebook. The students spent substantial amount of time on Facebook (2.31hours per day). Accordingly a possible explanation for the higher average time spend on social networking sites due to most students have visited social networking sites by using their personal Laptops and mobile phones and these create the opportunity to use social networking site for a long hours. Their study result 
also indicated that student's login Facebook approximately a mean of 3 times per day.

Mobile phone to login Facebook has a negative, moderate and significant relationship with university students GPA (Nebiat and Girum, 2014). Previous researches also indicated that mobile internet users are vulnerable to multitasking, using Facebook in conjunction with studying (Gloub and Miloloza, 2010) and multitasking activities are negatively associated with students' GPA (Ellis, Daniels and Jauregui,2010). Many studies also indicated that multitasking activities not only affect study times but also it reduces brain's ability to effectively retrieve information. Younger students tended to use Facebook more frequently than older students to keep in touch with friends from high school or from their hometown,

Research conducted by Yirga (2015), the purpose of internet usage in Asosa University, 13\% for mailing, $60 \%$ for chatting and the remaining $27 \%$ said that for posting purposes. Accordingly with regarding to membership of Facebook, 20.4\% use for finding new friends, $69.6 \%$ for communicating with the existing friends and the remaining $10.15 \%$ for academic purposes. In one day $8.5 \%$ of the students used social medias for about 1 (one) hour, and $63.9 \%$ of the students greater than 2 hours and $13.3 \%$ of the students we use social media for about 3-6 hours and the remaining $15.3 \%$ of the students for about $7-9$ hours.

\subsection{Positive Impacts of facebook on university students of Ethiopia}

Facebook is a social networking tool designed to boost the communication among its users. It is forming the students' social capital in various ways. Many researchers believe Facebook is good tool for socialization if you use it right. You can meet with people there and arrange meetings and easily discuss with others what to do when you'll see. You can share information related your studies if you like (groups). Facebook is good way to stay in contact with friends, families and relatives living far or near and you don't meet so often. It is also good platform to keep old friendships alive (Jibat, 2012).

University staffs and students can use Facebook for educational purposes and the study can direct the patterns of use. It will be quite interesting to investigate how professors and teachers are incorporating Facebook into their classrooms, long distance studies and learning projects. Facebook can facilitate informal communication around classroom activities and Facebook can facilitate collaboration among students (Ellison et al., 2007).

The important reasons for using Facebook are to keep in touch with relatives, friends, acquaintances, to keep in touch with classmates and for instant messaging. It is important to note that the high number of respondents using Facebook to maintain relationships with classmates, associated with the relatively average number of those using it to maintain relationships with teachers, provide new perspectives on the use of Facebook in the academic environment. A possible solution would be to use Facebook as an e-learning platform this idea supported by (Claudia, Vasile and Ciprian, 2016).

According to (Mesfin et al., 2017) to acquire a general satisfaction of social media since it encourages and facilitates student utilization of social media for collaborative learning, and boost the education and experience with students. In terms of interactivity with peers on social media and acquired a higher percentage when it comes to students' academic performance at university since it influences it to be simple for student to go over questions along with other students through social media. It is easy to networking with peers and interact with them because it is the same age, class and education level. The collaborative learning with social media usage and acquired an average percentage when it comes to academic performance of students at university. Since it helps make the students feel confident enough to presenting the social media by collaborative between peers, teachers and engagement within the class.

Research conducted by (Yirga 2015), indicate that the Facebook effect the deterioration of social norms and ethics in Ethiopia, from sampled students $59.1 \%$ of the respondents said that social media have an effect on the norm and ethics of Ethiopia and the remaining $40.9 \%$ of the respondents said that social medias does not any significance on the norm and ethics of Ethiopia. Accordingly the case of promoting information and knowledge $88.3 \%$ of the sampled students indicate that social media has an advantage, and the remaining $11.7 \%$ of the respondents' responded that it has no any significance on the promotion of information and knowledge. The other most important positive impacts of Facebook are:

$\checkmark \quad$ Bringing students together with varying backgrounds and encouraging them to extent experience to into real world function

$\checkmark$ Enabling those who can't leave their own houses

$\checkmark$ To meet other who has similar situations in addition to stay in touch with existing friends.

$\checkmark$ Giving why children a way to socialize extending, hopefully, into face-to-face interaction

$\checkmark$ Developing student self-identity through choosing profile photos, quotations and listing like and dislike.

$\checkmark$ Facebook make students feel much more comfortable and through free when sharing opinions and thoughts

$\checkmark \quad$ Reduce cost communication compared with direct call

$\checkmark \quad$ Easily get idea 
$\checkmark \quad$ Increases modernization and globalization

$\checkmark$ Get fashions and brand information easily

\subsection{Negative impacts of Facebook on university students of Ethiopia}

The excessive uses of Facebook are not only have long lasting effect on psyche of students but also affects the physical, mental and social aspect of life. Sometimes Facebook use also affects the academic achievement of the student because they don't want to leave that particular aura and thus their concentration stands divided. The time spent on Facebook was found to be heavily influenced by the attention span of the students. Specifically, we determined that the higher the attention online social networks, the lower are the time spent span. Further, attention span was found to be highly correlated with characteristics that predict or influence student behavior, such as their perceptions about society's view of social networking, their likes and dislikes of online social networks, ease of use of Online social networks idea is supported (Kennedy et al., 2009).

Providing ubiquitous facility of Social network is a straight invitation of addiction to any young and even an adult, as academic satisfaction is not enough for those students who suffers from social isolation (Yirga, 2015). The social network addict becomes a useless node for parents, friends and other associated people. They cannot succeed because they have no sense of upcoming future and competitions in their careers. Becoming addict of Facebook feels like you have so many friends but in real all of the contacts are virtual contacts. This act of going far from your family, friends, teachers and other associations could be very much dangerous for life and education. It changes the mindset of student completely like fantasies.

$\checkmark$ Young students might become narcissistic.

$\checkmark$ Developing psychological disorders like: antisocial behavior and aggressive tendencies.

$\checkmark$ Anxious, depression, higher absenteeism from school, stomach aches and sleep issues

$\checkmark$ Students who use Facebook once during the 15 minutes study time had lower test grades (distraction aspect).

$\checkmark \quad$ Spent wide time in using Facebook more than they spend on performing social and career duties.

$\checkmark$ Academic or career performances were declined since they used Facebook.

$\checkmark$ Students give priority to communicate with friends on Facebook over their social and career commitments.

$\checkmark \quad$ More time on Facebook equals slightly lower grade.

$\checkmark$ Using of Facebook caused loss of direct communication or face-to-face meeting with friends and relatives and Facebook user can give priority to communicate with friends on Facebook over their social and career commitments are negative impacts of Facebook.

\subsection{The relationship between times spend on Facebook and academic performance}

In educational institutions around the Ethiopia, students are joining online social network web based sites like Facebook, MySpace and LinkedIn and others. Today, Facebook is embraced of almost all types of internet users, but students from the universities and colleges are the largest percentage of active Facebook users, which is about $30 \%$ of all users (insidefacebook.com, 2009).

Facebook is a dynamic online social network site with various interactive features which not only attract the students but also facilitating them to bridge and bond new connections. Apparently Facebook is playing an important role in the process by which students form and maintain social capita (Ellison et al., 2007). It is also an influencing phenomenon among the university students playing vital role in the users' lives and on their academic performances.

It would be useful to mention a form of academic social capital focusing on academic life of the university students. According to Bourdieu and Wacquant (1992), social capital is "the sum of the resources, actual or virtual, that accrue to an individual or a group by virtue of possessing a durable network of more or less institutionalized relationships of mutual acquaintance and recognition. University students of Ethiopia have the accumulation of resources like courses materials, lectures, exams, friends, groups and extra curriculum activities etc. Now it is students own choice how they interact with these resources to gain social capital effectively.

Facebook invasion upon the students are now becoming the big challenge for educator and experts how to deal with. Facebook negatively affects GPA and study time spent per week. The most significant finding of this research is Facebook impact on student's GPA. Based on the findings, students who are involved in Facebook use has lower GPA than those who have not Facebook account or do not use Facebook. Although it is not very significant difference but still we can say Facebook is affecting students average grade point Kirschner and Karpinski (2010).

Facebook users are victim of distraction during their academic hours but in our findings there is no such evidence found. Most of the students use Facebook during their studies as a break and in their opinion Facebook does not distract them from doing studies or school work. Because Facebook is such an application that can run in the background of internet devices so users do not need to engage with Facebook constantly. Female students 
are more Facebook users than male students (Mesfin et al., 2017). Impairment of educational performance and internet dependency are correlated by utilizing synchronous communication programs including internet sites and forums. There are benefits and risks associated with using any social network.

Most students used a social media networking site on phone. This increased the approachability and flexibility of being in touch. Smart features available on social media networks like reading RSS feeds, location tagging and status updates were popular uses of social network on mobile phone. These were not directly related to education (Mesfin et al., 2017). In terms of the students' academic performance with engagement acquired a typical percentage when it comes to academic performance of students at University since it provides coalition and sharing of knowledge in the class and library by using of social media any time. The collaborative learning with social media usage and acquired an average percentage when it comes to academic performance of students at University. Since it helps make the students feel confident enough to presenting the social media by collaborative between peers, teachers and engagement within the class.

\subsection{The main reasons of university students of Ethiopia use Facebook}

Social media platforms are primarily used to connect people. They are suitable devices for sharing ideas, observations and experiences. It is feasible to comment, share, and review corporate or other individual messages with these media. University students use Facebook as a social network that allows interacting, publishing and sharing things, such as photos with friends. Moreover, students and every person can create a common profile, also allows users to visit the pages of friends. Moreover, users can exchange private messages, conversing among each other, posting images and videos, creating certain events and groups and inviting friends to join their groups. The power of Facebook lies in the method of spreading information from users; it offers a wide range of options in the broad exchange of information among users and this idea supported by research conducted by Kirschner and Karpinski (2010).

According to Yirga (2015), university students of social media or highly Facebook for mailing, chatting, posting purposes, finding new friends, for communicating with the existing friends and academic purposes. One of the most important features of Facebook page is "like" feature. It helps companies to broadcast corporate messages. In social media companies can communicate with its customers with this feature. In Ethiopia Facebook users agree "like"ing a company helps to know about the company more.

Some social media such as Wikipedia and to some extent blogs encourage investigative-based and collaborative activities among students in higher education institution of Ethiopia. This open access for active participation and can therefore create opportunities for effective learning. Linked with this principle of collaborative development among learners, social media enable learners and teachers to share and publish information as a result of the learning activity (e.g., course materials such as course syllabus, course notes, assignments, test cases) and invite feedback from peers. By publishing and presenting their work to a wide audience through blogs, wikis, or podcasts, learners benefit from the opportunity to appropriate new ideas, and transform their own understanding through reflection is supported by (Dale and Pymm, 2009).

According (Mesfin et., al 2017), Students use for chatting, for downloading music /video, searching assignment/quizzes, Uploading music $\backslash$ video, Blogging, Posting photos and Communication with teachers/class fellows was the least purpose used by the students. Accordingly downloading music and videos were not only educational but consisted of several genres. The highest score revealed that the students used it for chatting. Downloading music/videos, posting photos and chatting can be categorized as entertainment use. Educational activities like publishing articles, searching for assignment/quizzes, communicating with teachers comprised of a lesser score. This reflects that social media network were used by students for entertainment mostly and less for educational purposes.

Facebook is a social networking tool designed to boost the communication among their users. It is forming the students' social capital in various ways. Especially its availability on many mobile devices allows users to constantly stay in touch with friends, families and other associates as long as there is access to the Internet. It gives the opportunity to keep in contact with peoples constantly and influencing a person social capital. Facebook is a utility which is very effective for bridging, bonding and maintaining relations among the existing relations. Our results verify the statement that Facebook is playing important role to connect peoples.

According to Kirschner and Karpinski (2010), in simple mostly students are agree that they are particularly using Facebook to keep in touch with their friends which indicate that Facebook is playing vital role for bridging, bonding and maintain social capital among the known persons. Facebook is very effective tool for formation (bridging, bonding and maintaining) the students existing social capital but it is not very effective for most of the participant to increase social capital (make new friends). Due to huge popularity of online social network sites around the globe now researchers are exploring the phenomena with enthusiasm. Particularly Facebook invasion upon the students are now becoming the big challenge for educator and experts how to deal with is reason why university students of Ethiopia use Facebook. 


\section{Conclusion}

Social media is increasing way of communication in the Ethiopia and Facebook take the lion share of social media. Most common social media used by university student of Ethiopia are platforms Facebook, YouTube, Twitter, Instagram, Skype, Telegram, LinkedIn, Google+, and other similar interactive websites. Communication in Facebook is faster, better and efficient the credit goes largely to technology. Socialization is an important aspect of Facobook. The effects of increasing Facebook use on campus have mostly link with academic learning's and academic performances.

Developing psychological disorders, use Facebook as addiction, increase time spend on Facebook, long lasting effect on psyche of students but also affects the physical, mental and social aspect of life, predict or influence student behavior, such as their perceptions about society's view of social networking, their likes and dislikes of online social networks, Anxious, depression, higher absenteeism from school, stomach aches and sleep issues and Academic or career performances were declined are negative impacts of Facebook user in university students of Ethiopia.

Impairment of educational performance and social media dependency are correlated by utilizing synchronous communication programs including internet sites and forums. There are benefits and risks associated with using Facebook. Facebook user of university student uses it also for mailing, chatting and posting purposes. University students use Facebook also for academic accumulation of resources like courses materials, lectures, exams, friends, groups and extracurricular activities. Currently University students of Ethiopia use Facebook as a social network that allows interacting, publishing and sharing things, such as photos with friends. Moreover, students and every person can create a common profile, also allows users to visit the pages of friends.

\section{References}

Aliyas J, Hope M, Justin D, (2012). Effect of online social networking on student's academic performance. Journal of Computers in Human Behavior, (28) Page.2117-2127.

Błachnio, A., Przepiorka, A., Boruch, W., \& Bałakier, E. (2016). Selfpresentation styles, privacy, and loneliness as predictors of Facebook use in young people. Personality and Individual Differences, 94, 26-31. https://doi.org/10.1016/j.paid.2015.12.051.

Bourdieu, P, \& Wacquant, L (1992). An Invitation to Reflexive Sociology. Published: University of Chicago Press 1992.

C. Dale, \&J. Pymm. Podagogy - The iPod as a Learning Technology. Active Learning in Higher Education, 2009, 10, 84-96.

C. Dale, \&J. Pymm. Podagogy - The iPod as a Learning Technology. Active Learning in Higher Education, 2009, 10, 84-96.

Claudia Stoian, Vasile Gherhes and Ciprian Obrad, 2016. The Role and Importance of Facebook Among Students in Timișoara.

Dhir, A., \& Tsai, C. (2017). Understanding the relationship between intensity and gratifications of Facebook use among adolescents and young adults. Telematics and Informatics, 34, 350-364. https://doi. org/10.1016/j.tele.2016.08.017.

Ellis, Y., Daniels,B., Jauregui,A.(2010) The effect of Multi-tasking on grade performance of Business students, Research in Higher Education journal. Vol.8. Available at: http://www.aabri.com/manuscripts/10498.pdf. (Accessed 1 September 2011)

Ellison N, Steinfield C, and Lampe C, 2007. The benefits of Facebook "Friends:" social capital and college students' use of online social network sites. Journal of Computer-Mediated Communication, 12 (4), Page.1143-1168.

Ellison, N., Steinfield, C., \& Lampe, C. (2007). The benefits of Facebook 'friends': Social capital and college students' use of online social network sites. Journal of ComputerMediated Communication; 13(4), 114-116. doi:10.1111/j.1083-6101.2008.01432.x

Ethio Telecom. (2013). 2012/13 Annual Statistics Bulletin

Ethio Telecom. (2013). 2012/13 Annual Statistics of mobile and internet usage of Ethiopia

Facebook facts (2013). News room Facebook key facts. Retrieved Feb 20, 2013, from http://newsroom.fb.com/Key-Facts.

Feyisa Mulisa and Dawit Getahun, 2018. Perceived Benefits and Risks of Social Media: Ethiopian Secondary School Students' Perspectives.

G. Kennedy, B. Dalgarno, S. Bennet, K. Gray, et.al. 2009. Educating the Net Generation: A Handbook of Findings for Practice and Policy. Carlifornia, USA: Creative Commons.

G. Kennedy, B. Dalgarno, S. Bennet, K. Gray, et.al. 2009. Educating the Net Generation: A Handbook of Findings for Practice and Policy. Carlifornia, USA: Creative Commons.

Gloub,LT\&Miloloza,M.(2010) Facebook, academic performance, multitasking and Self-esteem. Available 
online facebook_academic_performance_multitasking_and_selfesteem.pdf. (Accessed 17 March 2012).

Grasmuck, S., Martin, J., \& Zhao, S. (2008). Identity construction on Facebook: Digital empowerment in anchored relationships. Computers in Human Behavior, 24(5). Retrieved from http://citeseerx.ist.psu.edu/viewdoc/download?doi=10.1.1.168.4349\&rep=rep1\&type=pdf

Grossman, Lev (2010). Person of the Year 2010 Mark Zukerberg. Retrieved on Mar 6, 2013 http://www.time.com/time/specials/packages/article/0,28804,2036683_2037183,00.html.

Internet Usage and Population Statistics for Africa, 2015.

Jibat T.(2012) Ethiopia: Is Facebook Advantageous? Available online at: http://allafrica.com/stories/201210190157.html. (Accessed 28 February 2013).

Kaplan A \& Haenlein, M. (2010). Users of the world, unite! The challenges and opportunities of Social Media. Journal of Business Horizons, 53(1), Page.59-68.

Kietzmann, H. (2012). "Social media? Get serious! Understanding the functional building blocks of social media". Business Horizons 54: 241-251.

Kirkpatrick, David. 2010. The Facebook effect: The inside story of the company that is connecting the world. Publishers: Simon \& Schuster, New York.

Kirschner P \& Karpinski A (2010). Facebook and academic performance. Journal of Computers in Human Behavior, 26, Page.1237-1245.

Lev-on, A. (2017). Telematics and informatics the third-person effect on Facebook: the significance of perceived proficiency. Telematics and Informatics, 34, 252-260. https://doi.org/10.1016/j.tele.2016.07. 002.

Lusk, B. (2010) Digital Natives and Social Media Behaviors: An Overview. The Prevention Research, Vol. 17. pp 3-6.

Martin, J.L.,\& Yeung, K., (2006.) Persistence of close personal ties over a 12-year period.Social Networks; 28, pp 331-362.

Mesfin Z., Tolosa D. Hirko T and Gadise G. 2017. The Impacts of Social Media on Academic Achievement of Female Students at Jimma University.

Nebait Negussie Corsalini and Girum Ketema Teklemariam, 2014. Relationship between Facebook Practice and Academic Performance of University Students.

Phillips, S. (2007). A brief history of Facebook. Guardian.co.uk. Retrieved from http://www.guardian.co.uk/technology/2007/jul/25/media.newmedia.

Porter. J. (2007). Facebook's Brilliant but Evil design. http://bokardo.com/archives/ facebooks-brilliant-but-evildesign/ (retrieved 27 April 2012).

Tsitsika, A. K., Tzavela, E. C., Janikian, M., Ólafsson, K., Iordache, A., Schoenmakers, T. M., \& Richardson, C. (2014). Online social networking in adolescence: patterns of use in six European countries and links with psychosocial functioning. Journal of Adolescent Health, 55, 141-147. https://doi.org/10.1016/j.jadohealth.2013.11. 010.

Yirga Yayeh. 2015. The Impact of Social Media's on Technology Students in Assosa University, Ethiopia. 